\title{
Localized magnetic inhomogeneities generation on defects as a new channel of damping for a moving domain wall
}

\author{
A. M. Gumerov ${ }^{1, \dagger}$, E. G. Ekomasov ${ }^{1,2}$, R. V. Kudryavtsev ${ }^{1,3}$, M. I. Fakhretdinov ${ }^{1}$ \\ †article@solitonlab.com \\ ${ }^{1}$ Bashkir State University, 32 Zaki Validi str., Ufa, 450076, Russia \\ ${ }^{2}$ South Ural State University (National Research University), 76 Lenina ave., Chelyabinsk, 454080, Russia \\ ${ }^{3}$ Institute of Molecules and Crystals Physics, Ufa Federal Research Center of RAS, 151 Oktyabrya ave., Ufa, 450075, Russia

\begin{abstract}
The paper presents theoretical studies on the domain wall energy losses that arise when it moves through the magnetic defect region. These losses are largely related to the generation of localized magnetization waves in the defect region. It is shown that the process of the domain wall energy scattering on the defect can be regarded as a new "channel of damping" for a domain wall. The study was carried out using numerical and analytical methods through the example of a three-layer model of the ferromagnetic structure, in which the intermediate layer differs in its physical parameters from the rest of the crystal. The intermediate layer (or magnetic defect) was simulated by a spatial modulation of the magnetic parameters. The modes of motion, in which "effective damping" is minimal, were calculated. The damping value depends on the excitation energy of the localized waves and is determined by the ratio of the defect properties and initial velocity of the domain wall motion. It is specifically shown that an increase in the domain wall energy loss is associated with the increase in the localized waves oscillations amplitude. In this case, the dependence of the localized waves oscillations amplitude on the domain wall initial velocity only has one maximum. It is at this point that the domain wall energy losses are maximal. They can be significantly reduced if the domain wall velocity is noticeably higher or lower than the maximum. This behavior was studied for both the point and extended defects.
\end{abstract}

Keywords: domain wall, sine-Gordon equation, three-layer magnetic, magnetic soliton generation, magnetic breather.

УДК: 537.611.3, 519.63

\section{Генерация локализованных магнитных неоднородностей на дефектах как новый канал затухания для движущейся доменной границы}

\author{
Гумеров А. М. ${ }^{1, \dagger}$, Екомасов Е. Г., ${ }^{1,2}$, Кудрявцев Р. В. ${ }^{1,3}$, Фахретдинов М.И. ${ }^{1}$ \\ ${ }^{1}$ Башкирский государственный университет, ул. 3. Валиди 32, Уфа, 450076, Россия \\ ${ }^{2}$ Южно-Уральский государственный университет, пр-т Ленина 76, Челябинск, 454080, Россия \\ ${ }^{3}$ Институт физики молекул и кристаллов УФИЦ РАН, пр-т Октября 151, Уфа, 450075, Россия
}

В работе теоретически изучаются потери энергии доменной границы, которые возникают при ее движении через область магнитного дефекта. Эти потери во многом связаны с генерацией локализованных волн намагниченности в области дефекта. В работе показано, что процесс рассеяния энергии доменной границы на дефекте можно рассматривать как новый «канал затухания» для доменной границы. Исследование проводилось с помощью численных и аналитических методов на примере трехслойной модели ферромагнитной структуры, в которой промежуточный слой отличается физическими параметрами от остального кристалла. Промежуточный слой (или магнитный дефект) моделировался с помощью пространственной модуляции магнитных параметров. Рассчитаны режимы движения, при которых «эффективное затухание» минимально. Величина этого затухания зависит от энергии возбуждения локализованных волн и определяется соотношением свойств дефекта и начальной скорости движения доменной границы. В частности, показано, что увеличение потерь энергии доменной границы связано с увеличением амплитуды колебаний локализованных волн. При этом зависимость амплитуды колебаний локализованных волн от начальной скорости доменной границы имеет только один максимум. Именно в этой точке потери энергии доменной границы максимальны. Их можно существенно уменьшить, если скорость движения доменной границы заметно больше или меньше максимума. Данное поведение рассчитывалось как для случая точечного, так и для случая протяженного дефекта.

Ключевые слова: доменная граница, уравнение синус-Гордона, трехслойный магнетик, генерация магнитных солитонов, магнитный бризер. 


\section{Introduction}

The recent surge of interest in magnetic solitons and breathers has been associated with the emergence of new experimental techniques that allow one to study the formation and propagation processes of nanometer-sized localized magnetization waves and their interaction with domain walls (DWs) [1-11]. Defects are good nucleation centers for the formation of localized magnetic inhomogeneities. The occurence of defects in magnetic materials is caused by the presence of structural and chemical inhomogeneities that break the perfect translational symmetry $[12,13]$. The presence of such defects leads to the occurence of local changes in the material parameters. In particular, in magnets local inhomogeneities of magnetic anisotropy (LIMA) and the exchange interaction parameter can form [12-18]. The change in magnetic parameters of the material in the defect region results in the change in the magnetic inhomogeneities structure, and in this region a distortion of the domain structure characteristic of the entire sample is observed. The experimental observation of such domain structure distortions is based on a method of determining defects in a crystal. When a DW passes through the region containing a defect, a part of its energy is expended on the excitation of localized magnetic inhomogeneities [19-21]. If there are many defects in the magnetic material, then the moving DW expends a lot of energy on the excitation of localized nonlinear magnetization waves and we can conclude about the presence of a new damping channel. It is significant that this issue has scarcely been studied in the literature. The classic term responsible for the damping of the magnetization vector in the Landau-Lifshitz equation is associated with the excitation of linear spin waves in a magnetic [13]. Also, multilayer magnetic structures that are of interest for practical applications are widely studied today [22]. They can represent periodically alternating layers of materials with different physical properties. It is instructive to study the dynamics of spin waves and magnetic inhomogeneities propagating in such systems. In the case of the magnetic inhomogeneities dynamics, perpendicular to the interfaces of the layers, one-dimensional models are often used [13]. The study of simple one-dimensional models is also important since it allows one to understand the effect of certain magnetic parameters on the process under consideration in real magnetic structures. When studying the magnetization dynamics with similar objectives, the presence of layers different from each other in the value of one or several magnetic parameters is often taken into account by the spatial modulation of the material magnetic parameters (see, for example, [19-21, 23]). In this case, the study of magnetic inhomogeneities in one-dimensional dynamics, under certain conditions, leads to finding a solution of the sine-Gordon type equation with variable coefficients that is encountered in many fields of modern physics [13, 24-28]. The study was carried out using numerical and analytical methods [29-32]. Due to the complexity of the problem, the researchers considered, as a rule, the modulation of only certain magnetic system parameters. For instance, they often took into account the magnetic anisotropy modulation both for the case of point and extended defects $[21,33]$. It is shown that when a DW passes through a thin magnetic layer with a lower anisotropy value, high-amplitude localized nonlinear waves of magnetization can arise in it $[19,33,34]$. The amount of energy expended on the excitation of localized waves determine the effective damping of the moving DW and can vary depending on the DW initial velocity. It is known that the frequency of the localized nonlinear waves excited in this case is practically independent of the DW initial velocity. But the velocity should effect the amplitude of the excited wave. In the present work, the structure, dynamics, and energy of localized nonlinear magnetization waves excited by the domain walls motion in a three-layer ferromagnetic structure have been studied.

\section{Basic equations and results}

A simple three-layer ferromagnetic structure consisting of two thick layers separated by a thin layer with a modified value of the anisotropy parameter is observed in the paper. The anisotropy parameter is assumed to be a function of the coordinate $x$ directed perpendicular to the layers interface. Thus, there is one magnetic «defect» in the system located in the $y z$ plane. The localized magnetic inhomogeneities and the domain wall are located in the $y z$ plane. Let us use spherical coordinates of the magnetization vector $\mathrm{M}(\cos \phi \sin \theta, \sin \phi, \cos \phi \cos \theta)$, where $\theta$ is the angle in the $y z$ plane between the direction of the magnetic moment vector and the axis of light magnetization ( $\mathrm{O} z$ axis), $\phi$ is the angle describing the exit of $M$ from the domain boundary plane. Taking into account the exchange interaction, uniaxial anisotropy, Zeeman energy in the ferromagnetic energy density, and assuming that $\phi=1$, the equation of motion for the magnetization in the angular variables can be represented in the following dimensionless form [23]:

$$
\frac{\partial^{2} \theta}{\partial t^{2}}-\frac{\partial^{2} \theta}{\partial x^{2}}+\frac{K(x)}{2} \sin 2 \theta=-h \sin \theta-\alpha \frac{\partial \theta}{\partial t} .
$$

When substituting $u=2 \theta$, equation (1) is the modified sine-Gordon equation (MSGE), $K(x)$ is the function describing the inhomogeneity of the anisotropy parameter, $h$ is the value of the external magnetic field directed along the $z$ axis, and $\alpha$ is the value of the damping parameter. The coordinate $x$ is normalized to the quantity $\delta_{0}$, where $\delta_{0}$ is the width of a static Bloch DW, the time $t$ is normalized to $\delta_{0} / c$, where $c$ is the limiting Walker velocity of stationary motion of the DW [12]. Let us consider the DW dynamics taking into account the possibility of localized magnetization waves excitation in the defect region during motion by inertia $(h=\alpha=0)$. First we consider the simplest case $K(x)=1-\varepsilon \delta(x)$, where $\delta(x)$ is the Dirac delta function, $\varepsilon$ is the constant that determines the change in the anisotropy parameter on the point defect. Then, for small $\varepsilon$, using the perturbation theory for the coordinates of the DW-center $X=X(t)$ and the amplitude localized at the magnetization wave defect $a=a(t)$, the following system of equations is obtained (see, for example, [35]):

$$
\left\{\begin{aligned}
8 \ddot{X}(t)+U^{\prime}(X)+a(t) F^{\prime}(X) & =0 \\
\ddot{a}(t)+\Omega^{2} a(t)+\frac{1}{2} \varepsilon F(X) & =0
\end{aligned}\right.
$$

where the following notations are introduced: 


$$
F(X)=2 \frac{\sinh X(t)}{\cosh ^{2} X(t)}, \quad F^{\prime}(X)=-2 \frac{\sinh ^{2} X(t)-1}{\cosh ^{3} X(t)} .
$$

and the «impurity mode» frequency is defined as:

$$
\Omega^{2}=1-\varepsilon^{2} / 4 \text {. }
$$

The system of equations (2) is a system of ordinary secondorder differential equations. It is much easier to analyze than the original equation (1). The first equation of system (2) describes the dynamics of the DW taking into account the presence of a defect and the magnetic inhomogeneity localized on it. The second equation of system (2) describes the dynamics of the localized magnetic inhomogeneity taking into account the presence of a defect and the DW. At present, the effect of localized waves on the DW dynamics is thoroughly studied $[13,23]$. We shall consider next the problem of the DW energy losses on the excitation of the localized magnetization waves on defects as the problem of a new damping channel for a moving DW.

\subsection{Dynamics of nonlinear waves localized in the defect region}

As has been shown before, at the scattering of a DW by a defect a part of its energy is expended on the excitation of a nonlinear magnetization wave localized in the defect region, or a "magnetic breather» (if the DW leaves the defect) [21, 33, 34]. Moreover, the magnitude of this energy can vary depending on the initial velocity of the DW $v_{0}$. Since the frequency of the excited wave is practically independent of $v_{0}[35], v_{0}$ can have an effect on its amplitude.

First, we shall consider the simplest case - the case of a point defect in the framework of model (2). From integration of equation (2) it can be seen that the breather oscillations amplitude can vary significantly (Fig. S1, supplementary material). Suppose that in this model the DW moves at a constant velocity $v_{0}$ and $X(0)=-10$. If we neglect the effect of the defect on the domain wall dynamics, then $X(t)$ can be written in the dimensionless form:

$$
X_{1}(t)=v_{0} t-10 \text {. }
$$

If we take into account the effect of the defect, neglecting only the localized wave excitation, then, by analogy with the solutions described in [36], the law of the DW motion can be represented in the form:

$$
X_{2}(t)=\operatorname{arsinh}\left[\frac{\sqrt{v_{0}^{2}+\varepsilon / 2}}{v_{0}} \cdot \sinh \left(v_{0} t-10\right)\right] .
$$

The graphs of the $X(t)$ dependence corresponding to (4) - (5) are shown in Fig. 1a,b, from which it can be seen that these dependences differ little for large values of $v_{0}$ (see curves 3 in Figs. 1a,b). However, in the region of small values of $v_{0}$, dependence (5) shows a better qualitative correspondence to the results of numerical simulation (see curves 1 in Fig. 1a,b).

Since the first collective coordinate $X(t)$ is described by formula (4), system (2) is reduced to a single equation for $a(t)$ :

$$
\ddot{a}+\Omega^{2} a=F(t)
$$

where

$$
F(t)=\varepsilon^{2} \frac{\sinh (X(t))}{\cosh ^{2}(X(t))} .
$$

Thus, this problem can be regarded as the excitation of a harmonic oscillator by external impulse $F(t)$. The $F(t)$ dependence for certain particular cases is shown in Fig. 1c, d. In this case, the initial conditions are as follows:

$$
X(0)=-10, \dot{X}(0)=v_{0}, a(0)=0, \dot{a}(0)=0 .
$$

To study (4)-(7) we use the Runge-Kutta numerical integration method. The time evolution $a(t)$ obtained is shown in Fig. S2 (supplementary material) from which it can be seen that the oscillations amplitude $a(t)$ differs considerably in the case of small $v_{0}$. We also calculate the oscillations maximum amplitude $A_{\max }$ of the breather for cases (4) and (5) and compare it with the values obtained by numerical integration of the initial system (2). Fig. 2 shows that when $v_{0} \rightarrow 1$, and the energy of the excited breather is much less than the total energy of the DW, both laws of the DW motion (4) and (5) describe well the calculations of the initial system (2). However, for small $v_{0}$, when the laws of motion differ significantly (see Figs. 1a, b, curves 1 ), the law of motion $X(t)=X_{2}(t)$ (5) provides much more accurate results, and is therefore used in further calculations.

Using the law of conservation of energy, an analytic expression for the breather vibrations amplitude for the case of a point defect can be found. Let the localized vibrational mode be given in the form [36]:
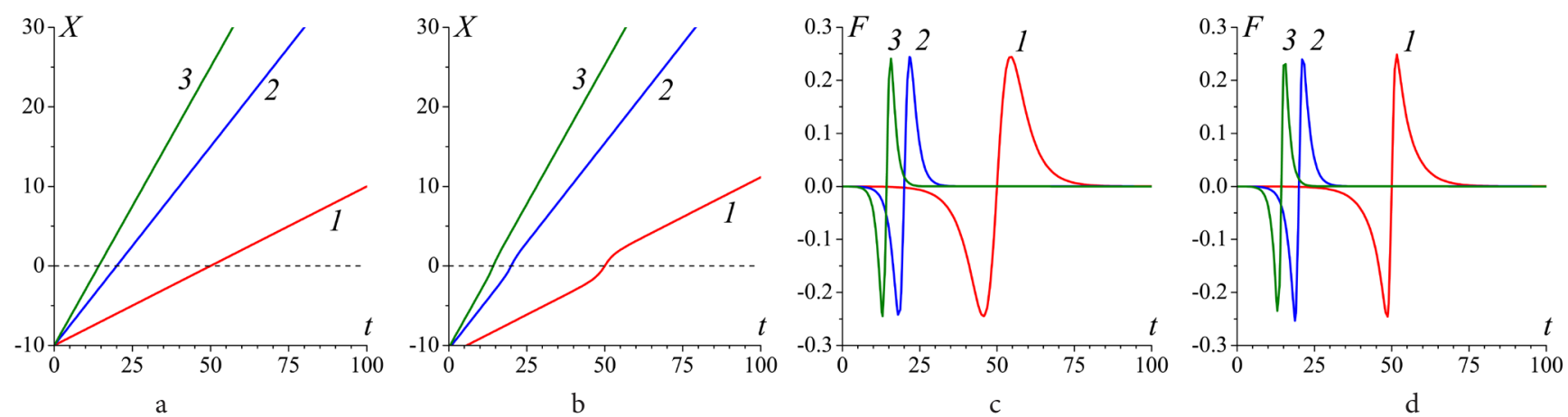

Fig. 1. The dependences $X(t)=X_{1}(t)$ (a) and $X(t)=X_{2}(t)$ (b) constructed according to expressions (4) and (5), respectively, and the dependence of $F(t)$ for $X(t)=X_{1}(t)(\mathrm{c})$ and $X(t)=X_{2}(t)(\mathrm{d})$ constructed according to expression (7). The parameters $\left.\left.\left.\varepsilon=0.7: 1\right) v_{0}=0.2,2\right) v_{0}=0.5,3\right) v_{0}=0.7$. 


$$
u(x, t)=B(t) \exp (-\varepsilon|x| / 2),
$$

where $B(t)=a_{0} \cos \left(\Omega t+\theta_{0}\right), \Omega$ is the frequency of impurity mode (3), and $\theta_{0}$ is the initial phase. Then the energy stored by the breather can be calculated as follows $[37,38]$ :

$$
E_{i m}=\frac{1}{2} \int_{-\infty}^{\infty}\left\{\left(\frac{\partial u_{i m}}{\partial t}\right)^{2}+\left(\frac{\partial u_{i m}}{\partial x}\right)^{2}+[1-\varepsilon \delta(x)] u_{i m}^{2}\right\} d x=\frac{\Omega^{2} a_{0}^{2}}{\varepsilon} .
$$

Suppose that the variation of $X(t)$ is described by the solution of [36]:

$$
X(t)=\operatorname{arsinh}\left(\gamma \sinh \left(v_{0} t\right)\right) .
$$

where $\gamma=\sqrt{1+\varepsilon /\left(2 v_{0}^{2}\right)}$. Then the force acting on the breather (oscillator) is given by the expression (taking into account (7)):

$$
f(t)=\frac{\varepsilon^{2} A \sinh \left(v_{0} t\right)}{1+A^{2} \sinh \left(v_{0} t\right)} .
$$

If we go over to the complex variable: $\xi(t)=\dot{a}+i \Omega t$, then the oscillation equation (6) can be reduced to the form:

$$
\dot{\xi}-i \Omega \xi(t)=f(t)
$$

which has the solution [37]:

$$
\xi(t)=e^{i \Omega t} \int_{-\infty}^{t} f(\tau) e^{-i \Omega \tau} d \tau,
$$

with the initial conditions $a(-\infty)=\dot{a}(-\infty)=0$, i.e. the oscillator (breather) is absent before the interaction. The total energy transferred from the particle (DW) to the oscillator (breather) can be found in the form [37]:

$E_{\text {im }}=2 \pi^{2} \varepsilon^{2} \sinh ^{2}\left[\frac{\Omega}{2 V} \arccos \left(\frac{2 v_{0}^{2}-\varepsilon}{2 v_{0}^{2}+\varepsilon}\right)\right] \cosh ^{-2}\left(\frac{\Omega \pi}{2 v_{0}}\right)$.

Then from (9) and (14) we obtain the following expression for the breather amplitude:

$a_{0}^{2}=\frac{2 \pi^{2} \varepsilon^{2}}{\Omega^{2}} \sinh ^{2}\left[\frac{\Omega}{2 V} \arccos \left(\frac{2 v_{0}^{2}-\varepsilon}{2 v_{0}^{2}+\varepsilon}\right)\right] \cosh ^{-2}\left(\frac{\Omega \pi}{2 v_{0}}\right)$.

Expression (15) describes well the results obtained by numerical integration of system (2) (Fig. 3). However, the obtained dependences are very far from the breather amplitude of model (1). Despite this, the nature of the dependences is qualitatively the same: there is one maximum on all curves in Fig. 3, which is supposedly related to the shape ratio of external pulse $F(t)$ and the shape of potential $U(X)$. And the maximum point depends on the defect parameters.

A similar behavior is also observed for the case of extended defects, for example, of the form:

$$
K(x)=\left\{\begin{array}{cc}
1, & x<x_{0}, x>x_{0}+W, \\
1-\Delta K, & x_{0}<x<x_{0}+W,
\end{array}\right.
$$

where $W$ is the width of the «inhomogeneity» region of the periodic potential the left boundary of which is at point $x_{0}$.

From Fig. 4, which shows the dependence of the maximum amplitude of the excited breather, it is seen that there also is a single maximum on all curves. However, the amplitude change is more significant in comparison with the point defect.
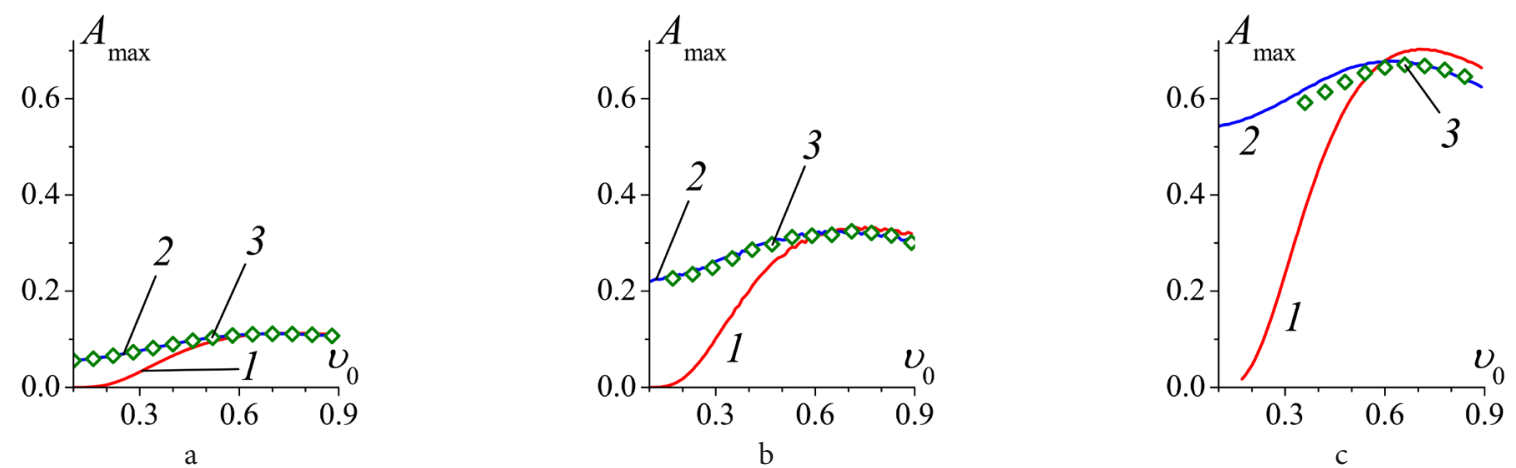

Fig. 2. The maximum amplitude of the breather vibrations $A_{\max }$ as a function of the initial velocity of the DW $v_{0}$ at $\varepsilon=0.3$ (a), $\varepsilon=0.5$ (b) and $\varepsilon=0.7$ (c) calculated by the numerical integration: 1) of equation (6) by the motion law of the DW (4), 2) of equation (6) by the motion law of the DW (5), 3) of the equations system (2).
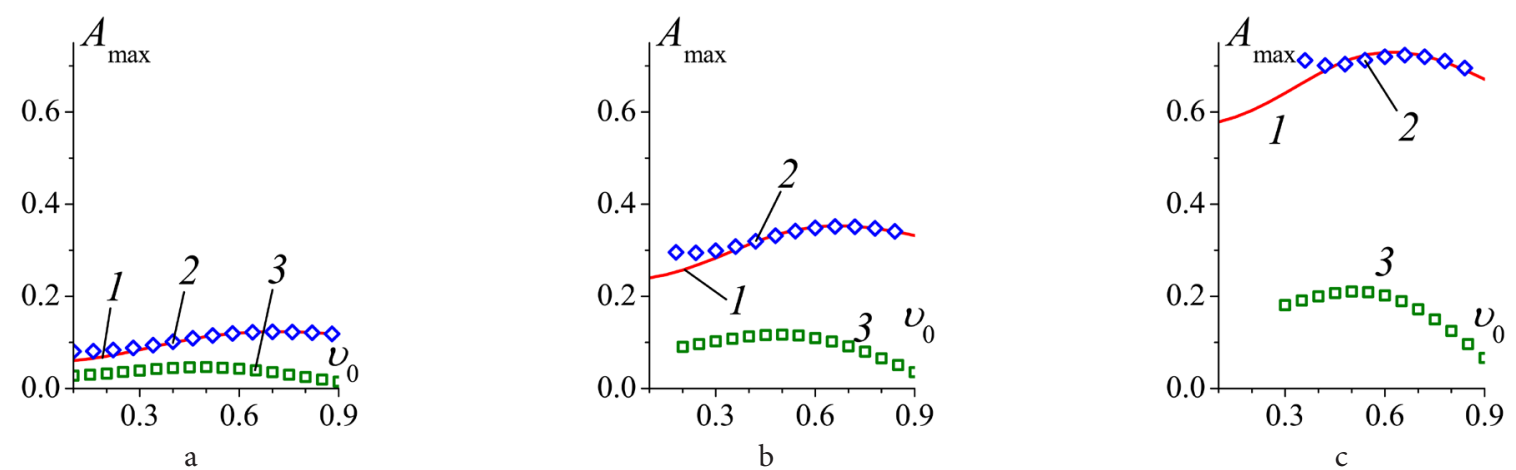

Fig. 3. The maximum amplitude of the breather vibrations $A_{\text {max }}$ as a function of the initial velocity of the DW $v_{0}$ at $\varepsilon=0.3$ (a), $\varepsilon=0.5$ (b) and $\varepsilon=0.7$ (c), calculated: 1) from the analytical expression (15),2) by integrating the equations system (2), 3) by the numerical simulation of equation (1). 

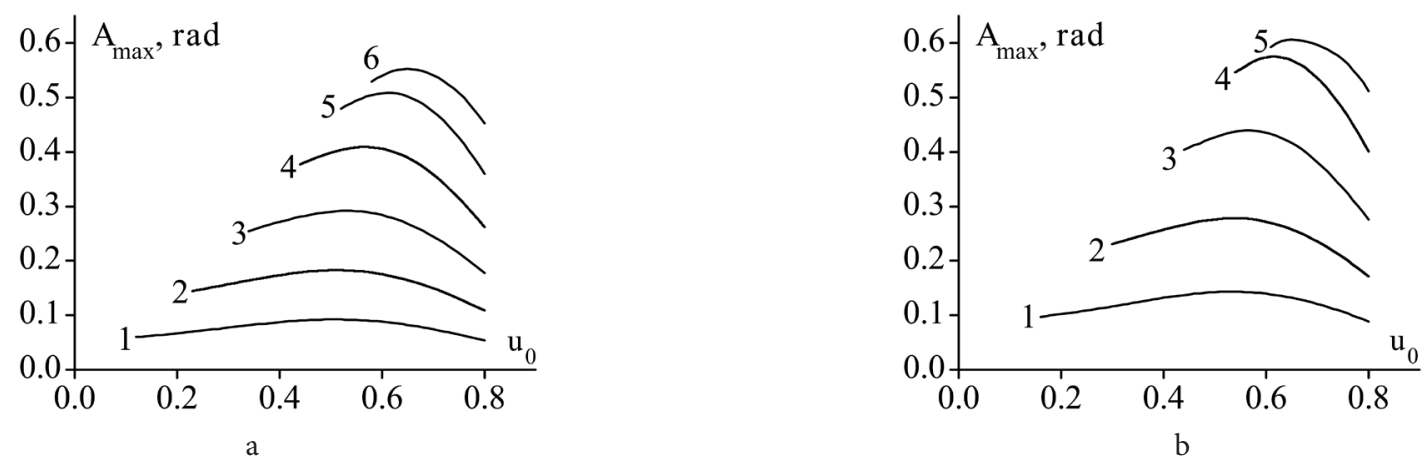

Fig. 4. The maximum amplitude of the breather $A_{\max }$ at the defect center of the form (16) as a function of the initial DW velocity $v_{0}$ and at $W=1$ (a) and $W=1.5$ (b). Curves $1-6$ correspond to the cases $\Delta K=0.5,0.75,1,1.25,1.5,1.75$, respectively.

\section{Conclusion}

The study shows that the process of DW energy scattering on a defect can be regarded as a new «channel of damping» for a moving domain wall. The dependence of the magnetic breather amplitude value on the initial velocity of the DW with only one maximum on it is calculated. Since the increase in the DW energy losses is associated with the increase in the amplitude of the magnetic breather oscillations, then, the energy losses are maximal at the DW critical velocity $v_{0}$ corresponding to the maximum of this dependence. The DW energy losses can be substantially reduced if the DW motion velocity is noticeably different decreasingly or increasingly in comparison with the critical one. Physically, the mechanism is important in reducing energy losses on the excitation of local magnetic inhomogeneities and can also be used to describe the dynamics of the magnetic breathers excitation in real crystals in which many small defects occur. Energy losses during DW motion increase with increasing defect parameters and are most noticeable in extended defects.

Acknowledgements. The work was supported by Act 211 Government of the Russian Federation, contract 02. A03.21.0011. For A.M. G. and R.V. K. the work was supported by the RFBR grant, project 18-31-00122.

Supplementary Material. The on-line version of this paper contains supplementary material (figures) available free of charge at the journal's Web site (www.lettersonmaterials.com).

\section{References}

1. K.S. Novoselov, S.V. Dubonos, S.V. Morozov, D. V. D. Bergen, J. K. Maan, A. K. Geim. Int. J. Nanosci. 3, 87 (2004). DOI: 10.1142/S0219581X04001857

2. K.S. Novoselov, S. V. Dubonos, E. Hill, A.K. Geim. Physica E Low Dimens Syst Nanostruct. 22, 406 (2004). DOI: $10.1016 /$ j.physe.2003.12.032

3. K.S. Novoselov, A.K. Geim, S.V. Dubonos, E.W. Hill, I.V. Grigorieva. Nature. 426, 812 (2003). DOI: $10.1038 /$ nature 02180

4. K. S. Novoselov, A. K. Geim, van der Berg, S. V. Dubonos, J.K. Maan. IEEE Trans. Magn. 38, 2583 (2002). DOI: 10.1109/TMAG.2002.801959

5. R. Kukreja, S. Bonetti, Z. Chen, D. Backes, Y. Acremann,
J.A. Katine, A.D. Kent, H.A. Dürr, H. Ohldag, J. Stöhr. Phys. Rev. Lett. PRL. 115, 096601 (2015). DOI: 10.1103/PhysRevLett.115.096601

6. J.P. Tetienne, T. Hingant, J.V. Kim, L.H. Diez, J.P. Adam, K. Garcia, J. F. Roch, S. Rohart, A. Thiaville, D. Ravelosona, V. Jacques. Science. 344, 1366 (2014). DOI: $10.1126 /$ science. 1250113

7. J. Rusz, S. Muto, J. Spiegelberg, R. Adam, K. Tatsumi, D.E. Bürgler, C. M. Schneider. Nat. Commun. 7, 12672 (2016). DOI: 10.1038/ncomms 12672

8. M.V. Gerasimov, M.V. Logunov, A.V. Spirin, Yu. N. Nozdrin, I. D. Tokman. Phys. Rev. B. 94, 014434 (2016). DOI: 10.1103/PhysRevB.94.014434

9. A.V. Golovchan, V.V. Kruglyak, V.S. Tkachenko, A. N. Kuchko. Royal Society open science. 5(1), 172285 (2018). DOI: 10.1098/rsos.172285

10. L. Kavitha, E. Parasuraman, D. Gopi, A. Prabhu, R.A. Vicencio. Journal of Magnetism and Magnetic Materials. 401, 394 (2016). DOI: $10.1016 /$ j.jmmm.2015.10.021

11. L. Kavitha, A. Mohamadou, E. Parasuraman, D. Gopi, N. Akila, A. Prabhu. Journal of Magnetism and Magnetic Materials. 404, 91 (2016). DOI: $10.1016 /$ j.jmmm.2015.11.036

12. A. Hubert and R. Schafer. Magnetic Domains. Springer, Heidelberg (1998) 720 p.

13. M.A. Shamsutdinov, V.N. Nazarov, I. U. Lomakina, A.T. Kharisov, D.M. Shamsutdinov. Ferro- and antiferromagnitodinamika. Nonlinear Oscillations, wavesand solitons. Moscow, Nauka (2009) 456 p. (in Russian) [М.А. Шамсутдинов, И.Ю. Ломакина, B.Н. Назаров, А.Т. Харисов, Д. М. Шамсутдинов. Ферро- и антиферромагнитодинамика. Нелинейные колебания, волны и солитоны. Москва, Наука (2009) 456 c.]

14. M. A. Shamsutdinov, V.G. Veselago, M.M. Farztdinov, E. G. Ekomasov. Phys. Solid State. 32, 288 (1990). (in Russian) [M.А. Шамсутдинов, В.Г. Веселаго, М.М. Фарзтдинов, Е.Г. Екомасов. ФТТ. 32(2), 497 (1990).]

15. V.V. Plavskii, M.A. Shamsutdinov,E.G. Ekomaso v, A.G. Davletbaev. Phys. Met. Metallogr. 75, 589 (1993). (in Russian) [В.В. Плавский, Е.Г. Екомасов, М. А. Шамсутдинов, А. Г. Давлетбаев. ФММ. 75(6), 26 (1993).] 
16. Y. Sun, R. Gao. Solid State Commun. 149, 393 (2009). DOI: $10.1016 /$ j.ssc.2008.12.015

17. B. N. Filippov, M. N. Dubovik. Phys. Solid State. 56, 967 (2014). DOI: 10.1134/S1063783414050084

18. M.N. Dubovik, L.G. Korzunin, B.N. Filippov. The Physics of Metals and Metallography. 116, 656 (2015). DOI: 10.1134/S0031918X16040049

19. E.G. Ekomasov, A.M. Gumerov, R.R. Murtazin, R. V. Kudryavtsev, A.E. Ekomasov, N.N. Abakumova. Solid State Phenomena. Switzerland. Trans Tech Publications. 233-234, 51 (2015). DOI: $10.4028 /$ www.scientific.net/SSP.233-234.51

20. E. G. Ekomasov, R. R. Murtazin, V.N. Nazarov. Journal of Magnetism and Magnetic Materials. 385, 217 (2015). DOI: $10.1016 /$ j.jmmm.2015.03.019

21. E.G. Ekomasov, A.M. Gumerov. Letters on materials. 4(4), 237 (2014). (in Russian) [Е.Г. Екомасов, А. М. Гумеров. Письма о материалах. 4(4), 237 (2014).] DOI: $10.22226 / 2410-3535-2014-4-237-240$

22. D.D. Tang, Yu.-J.Le. Magnetic Memory Fundamentals and Technolog. Cambridge, Cambridge University Press, New York (2010) 196 p.

23. E.G. Ekomasov, R.V. Kudryavtsev, A.M. Gumerov. Letters on Materials. 7(2), 160 (2017). (in Russian) [Е.Г. Екомасов, Р.В. Кудрявцев, А.М. Гумеров. Письма о материалах. 7(2), 160 (2017).] DOI: $10.22226 / 2410-3535-2017-2-160-164$

24. A. B. Borisov, V. V. Kiselev. Nonlinear waves, solitons and localized structures in magnetic materials. T.1. Quasi-onedimensional magnetic solitons. UB RAS, Ekaterinburg (2009) 512 p. (in Russian) [А. Б. Борисов, В.В.Киселёв. Нелинейные волны, солитоны и локализованные структуры в магнетиках. Т.1. Квазиодномерные магнитные солитоны. УрО РАН, Екатеринбург (2009) 512 c.]

25. J. Cuevas-Maraver, P.G. Kevrekidis, F. Williams (Eds.). The Sine-Gordon Model and Its Applications: From Pendula and Josephson Junctions to Gravity and High- energy Physics, V. 10. Springer (2014) 263 p.

26. J.A. González, A. Bellorin, M.A. García-Ñustes, L. E. Guerrero, S. Jiménez, L. Vázquez. Physics Letters A. 381(24), 1995(2017). DOI: 10.1016/j.physleta.2017.03.042

27. J.A. González, A. Bellorin, L.E. Guerrero. Physical Review E. 65(6), 065601 (2002). DOI: 10.1103/PhysRevE.65.065601

28. V.A. Gani, A.E. Kudryavtsev. Physical Review E. 60(3), 3305 (1999). DOI: 10.1103/PhysRevE.60.3305

29. V.A. Gani, A.E. Kudryavtsev, M.A. Lizunova. Physical Review D. 89(12), 125009 (2014). DOI: 10.1103/PhysRevD.89.125009

30. A. Askari, D. Saadatmand, K. Javidan. Waves in Random and Complex Media. 1-14 (2018). DOI: $10.1080 / 17455030.2018 .1439203$

31. K. Javidan. Physical Review E. 78(4), 046607 (2008). DOI: 10.1103/PhysRevE.78.046607

32. S.P. Popov. Computational Mathematics and Mathematical Physics. 58(3), 437 (2018). DOI: $10.1134 /$ S0965542518030107

33. E.G. Ekomasov, A.M. Gumerov, R.V. Kudryavtsev. Letters on materials. 6(2), 138 (2016). (in Russian) [Е.Г. Екомасов, А.М. Гумеров, Р.В. Кудрявцев.

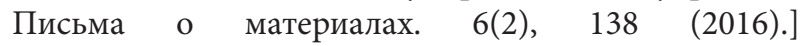
DOI: $10.22226 / 2410-3535-2016-2-138-140$

34. E.G. Ekomasov, A.M. Gumerov, R. V. Kudryavtsev. JETP Letters. 101, 835 (2015). DOI: $10.1134 /$ S0021364015120061

35. E. G. Ekomasov, Sh.A. Azamatov, R.R. Murtazin. Phys. Met. Metallogr. 105(4), 313 (2008). DOI: 10.1134/S0031918X08040017

36. T. Dauxois, M. Peyrard. Physics of Solitons. N.Y., Cambridge University Press (2010).

37. Y. S. Kivshar, F. Zhang, L. Vazquez. Phys. Rev. Lett. 67,1177 (1991). DOI: 10.1103/PhysRevLett.67.1177

38. O. M. Brown, J. S. Kivshar. The Frenkel-Kontorova model: Concepts, methods, and applications. Springer (2004) 519 p. 